\title{
Histopathologic and Immunohistochemical Characterization of Human Gastric Oxyntic Mucosa with Parietal Cell Protrusions and Investigation into the Association Between Such Mucosal Changes of the Stomach and Use of Proton Pump Inhibitors
}

\author{
Saeko Naruki ${ }^{1}$, Takashi Fujino ${ }^{1}$, Shigeko Ohnuma ${ }^{1}$, Akira Endo ${ }^{1}$, \\ Hirotaka Koizumi ${ }^{1}$, Yo Kato ${ }^{2}$, and Masayuki Takagi ${ }^{1}$
}

(Received for Publication: June 25, 2015)

\begin{abstract}
With widespread use of proton pump inhibitors (PPIs) has come characteristic gastric mucosal changes such as parietal cell protrusions (PCPs) and so-called fundic gland polyps (FGPs). Nevertheless, whether these lesions are actually PPI-related gastric mucosal lesions has not been fully clarified. The present study focused on this issue. We firstly examined the purported relation between the emergence of PCPs and PPI use. We also investigated the relation between PPI use and the emergence of cystically dilated glands (CDGs) that can give rise to elevated mucosal lesions such as FGPs. In addition, we performed histopathologic and immunohistochemical analyses to clarify the characteristics of PCPs and PCP-affected gastric oxyntic mucosa. A significant relation between the emergence of PCPs and PPI use was confirmed. In contrast, no significant relation was found between the emergence of CDGs and PPI use. Histologic and immunohistochemical analyses showed PCPs to be hyperplastic lesions. In the PCP-affected oxyntic mucosa, the isthmus-and-neck region of the fundic glands was elongated and the base region was shortened in relation to the total mucosal thickness. These changes were accompanied by an increase in the number of parietal cells and a decrease in the number of chief cells. Immunohistochemical analysis suggested impairment of both parietal cell differentiation and mucous neck-to-chief cell differentiation. Furthermore, our study reinforced the notion that elevated hydrostatic pressure and cytoplasmic edema due to movement of water from interstitial space toward the lumen of oxyntic glands via parietal cells give rise to the formation of PCPs, oxyntic dilatation, and CDGs. The detailed mechanism of PCP formation and its clinical implications are expected to be clarified in future studies.
\end{abstract}

\section{Key words}

stomach, proton pump inhibitor, oxyntic mucosa, parietal cell protrusion, dilated fundic gland

\section{Introduction}

Human gastric oxyntic mucosa is characterized by pits (foveolae), which are invaginations of the surface epithelium that open into long glands. Each gland is made up of 3 regions: an isthmus, neck, and base $^{1)}$. As illustrated in Figure 1, the pit is lined by foveolar cells (mucus-secreting cells). The isthmus is composed mainly of oxyntic epithelial progenitors (proliferating cells). The neck is composed of a mixture of mucous neck cells and parietal cells (gastric acid-secreting cells), and the base is composed mainly of chief cells (pepsinogen-secreting cells). The parietal cells extend mainly from the isthmus to the base.

Proton pump inhibitors (PPIs) are a class of

1 Department of Pathology, St. Marianna University School of Medicine

2 Department of Pathology, Nikko Medical Center, Dokkyo Medical University 


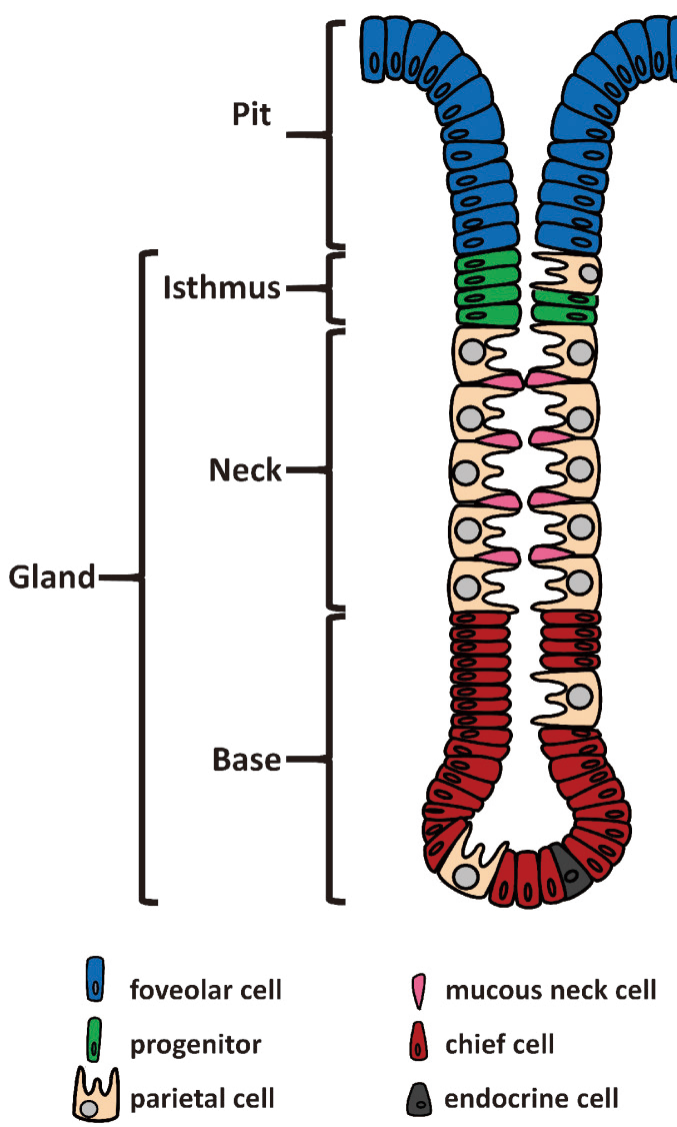

Figure 1. Schematic diagram (anatomy) of oxyntic mucosa.

The luminal surface of the oxyntic mucosa displays orifices that lead to tubular invaginations called pits, at the bottom of which open 1 or more glands. Each gland is divided into 3 regions: isthmus, neck, and base. The pit is lined by foveolar cells (mucus-producing cells). The isthmus is composed mainly of oxyntic epithelial progenitors (proliferating cells). The neck is characterized by a mixture of mucous neck cells and parietal cells (gastric acid secretion cells). The base is composed mainly of chief cells (pepsinogen secretion cells). Parietal cells extend mainly from the isthmus to the base.

medicines used to control and treat gastrointestinal peptic ulcer disease by blocking acid secretion ${ }^{2}$. Introduced in the 1980s, PPIs suppress secretion of gastric acid by parietal cells, and they do this by targeting the enzymatic function of gastric $\mathrm{H}^{+} / \mathrm{K}^{+}$-ATPase (proton pump) without influencing histamine receptor, gastrin receptor, or acetylcholine receptor path- ways. PPIs, marketed as omeprazole or lansoprazole, became widely available in the early 1990s and, with their potent suppression of gastric acid secretion, prevailed over $\mathrm{H} 2$ blockers ${ }^{2}$. PPIs are now commonly used in the treatment of gastric acid-related diseases including gastric ulcer, duodenal ulcer, and reflux esophagitis. PPIs are also used adjuvantly in the eradication of H. pylori ${ }^{3}$.

With widespread use of PPIs came reports of gastric mucosal changes including fundic gland hyperplasia $^{4}$, cystic dilation of fundic glands (oxyntic dilatation $)^{5 / 6)}$, emergence and enlargement of socalled fundic gland polyps (FGPs) ${ }^{7-11)}$, and morphologic changes in parietal cells ${ }^{12}$. The parietal cell protrusions (PCPs) found in patients treated with omeprazole are thought to be an especially characteristic change ${ }^{13-15)}$. PCP describes marked convex protrusion of parietal cell cytoplasm into the lumen of the oxyntic glands. Oxyntic glands affected by PCP tend to dilate (oxyntic dilatation) (Figure 2A), and the cytoplasm of the involved parietal cells often appears vacuolated (Figure 2B). PCPs have been observed frequently in patients receiving maintenance therapy with omeprazole or lansoprazol ${ }^{13-16)}$. Socalled FGPs, which are characterized histologically by cystically dilated glands (CDGs), are also observed in patients receiving maintenance PPI therapy ${ }^{7-11), 17)}$. In fact, Cats et al. reported that most of their patients with dilated fundic glands showed PCP during omeprazole maintenance therapy ${ }^{15}$. It is our understanding that the morphology of parietal cells in CDGs in patients taking PPIs clearly differs from that of sporadic FGPs in patients not taking PPIs (Figure 3), indicating that the formation of CDGs with PCP differs etiologically from the formation of sporadic FGPs.

We know of no reported investigation of PCP development in patients taking PPIs versus patients not taking PPIs. We conducted a comparative study to clarify the characteristics and histogenesis of PCP itself and of oxyntic mucosa with PCPs in humans.

\section{Materials and Methods}

\section{Case selection}

We reviewed all endoscopically obtained biopsy specimens of gastric oxyntic mucosa from 468 patients examined for various gastrointestinal disorders at St. Marianna University School of Medicine Hospital, Kanagawa, Japan, in 2013. In addition, we reviewed the records of these patients to determine which had been prescribed a PPI (omeprazole, lanso- 

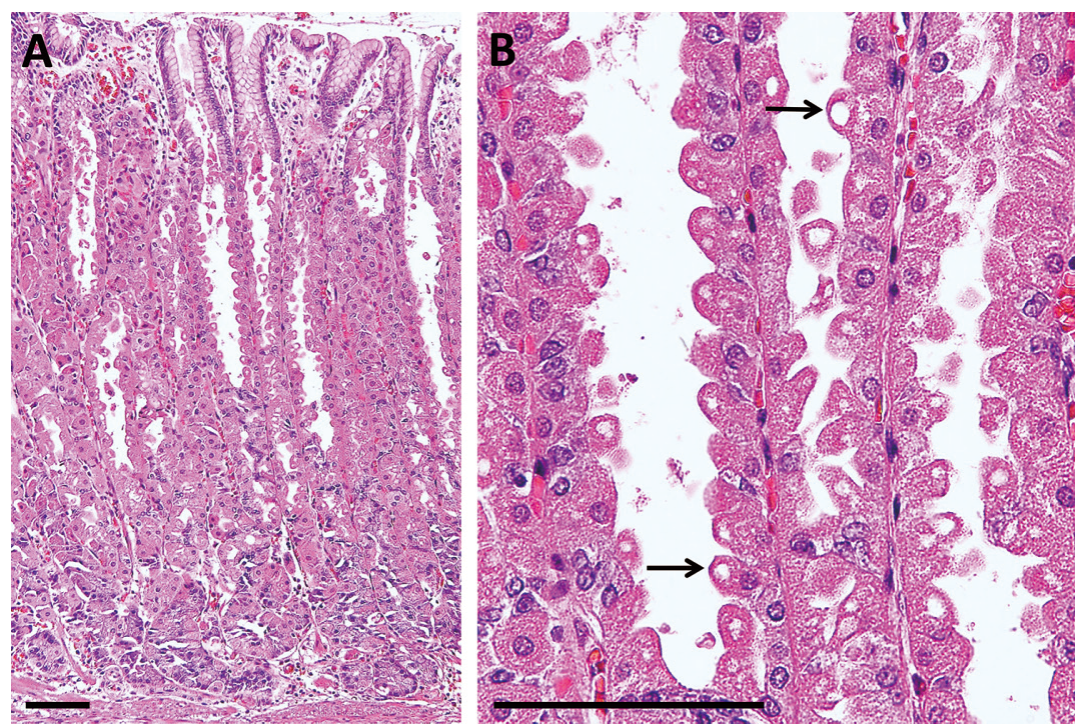

Figure 2. Characteristics of PCPs.

Representative histologic images of oxyntic mucosa with PCPs. A, Parietal cells show marked intraluminal protrusion of cytoplasm resulting in a serrated glandular lumen. The affected fundic glands tend to dilate (oxyntic dilatation) (H\&E stain, low magnification). B, Parietal cells show tongue-like convex protrusion. Note the protrusion of parietal cell cytoplasm into the lumen and the accompanying vacuolation (arrow) (H\&E stain, high magnification). Each black bar $=100 \mu \mathrm{m}$
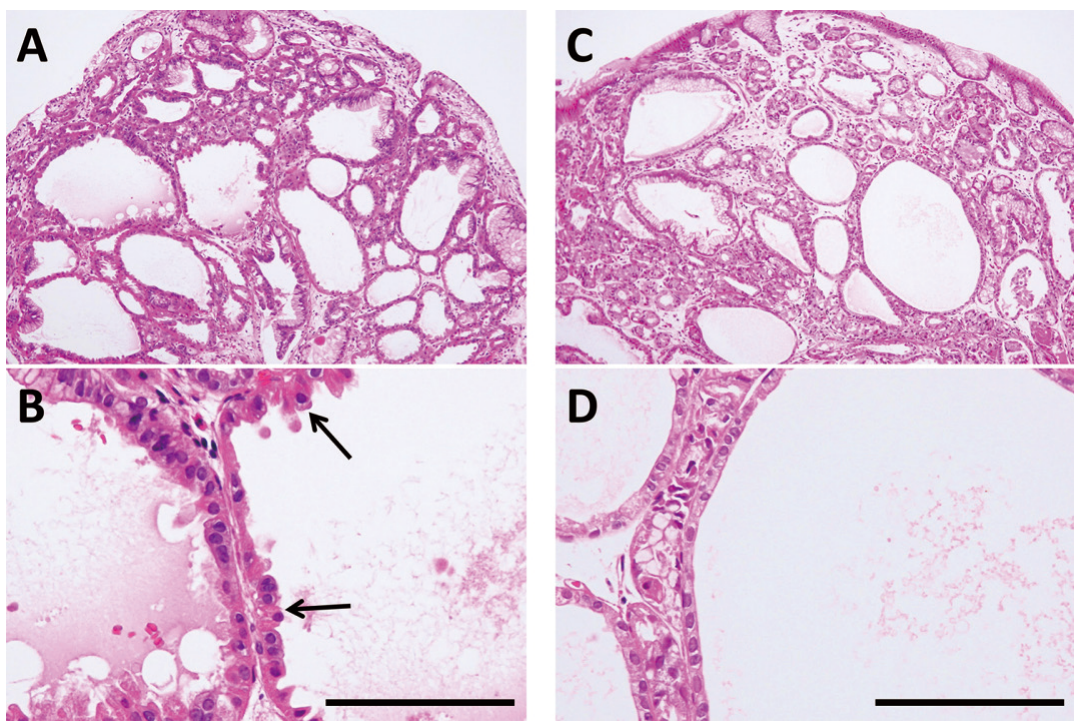

Figure 3. Histologic comparison of CDGs with PCPs and with sporadic FGPs.

Representative histologic images of CDGs with PCPs (H\&E stain). A, Low magnification. B, High magnification. Note the protruding parietal cells (arrows). Representative histologic images of a sporadic FGP (H\&E stain). C, Low magnification. D, High magnification. Note the flattening of epithelial cells in the CDGs. Each black bar $=100 \mu \mathrm{m}$ 
prazole, sodium rabeprazole, esomeprazole) during the 1-year period before the biopsy was performed, and we classified these patients according to whether they had $(n=127)$ or had not $(n=341)$ used PPIs.

We also reviewed surgical specimens containing gastric oxyntic mucosa from 52 patients who underwent open gastrectomy at St. Marianna University School of Medicine Hospital or Toyoko Hospital, Kanagawa, Japan, between January 2011 and December 2013. These patients, none of which had atrophic gastritis, were divided into 2 groups: those in whom PCPs were present $(\mathrm{n}=26, \mathrm{PCP}(+)$ group) and those in whom PCPs were not present $(\mathrm{n}=26, \mathrm{PCP}(-)$ group). The $\mathrm{PCP}(+)$ group included 22 men $(85 \%)$ and 4 women $(15 \%)$ with a median age of 67 years (range: $27-84$ years), and the $\mathrm{PCP}(-)$ group included 19 men (73\%) and women (27\%) with a median age of 70 years (range: $40-87$ years). Only specimens obtained from the lesser curvature of the corpus were examined.

The study protocol was approved by the Human Ethics Review Committee of St. Marianna University School of Medicine.

\section{Histology and immunohistochemistry}

All tissue specimens were fixed in 10\% formalin and embedded in paraffin. For histopathologic examination, 4- $\mu$ m-thick sections were cut from the paraffin blocks and stained with hematoxylin and eosin (H\&E).

Immunohistochemistry was performed with the following primary antibodies: anti-MUC5AC antibody (CLH2, mouse monoclonal, dilution: 1:100; Leica Microsystems, Wetzlar, Germany), anti-AQP4 antibody (AB3594, rabbit polyclonal, dilution: 1:500; Merick Millipore, Billerica, Massachusetts, USA), anti- $\mathrm{H}^{+} / \mathrm{K}^{+}$-ATPase antibody $(1 \mathrm{H} 9$, mouse monoclonal, dilution: 1:10000; Medical \& Biological Laboratories, Aichi, Japan), anti-MUC6 antibody (CLH5, mouse monoclonal, dilution: 1:100; Leica Microsystems), anti-MIST1 antibody (LS-B10140, rabbit polyclonal, dilution: 1:5000; LifeSpan BioSciences, Seattle, Washington, USA), and anti-Ki-67 antibody (MIB-1, mouse monoclonal, dilution: 1:200; Dako, Glostrup, Denmark). For antigen retrieval, the paraffin sections were heated to $95^{\circ} \mathrm{C}$ for 40 minutes in $\mathrm{pH}$ 6.0 citrate buffer for primary antibodies against MUC5AC, $\mathrm{H}^{+} / \mathrm{K}^{+}$-ATPase, MUC6, and $\mathrm{Ki}-67$ or to $95^{\circ} \mathrm{C}$ for 40 minutes in $\mathrm{pH} 9.0$ citrate buffer for primary antibody against MIST1. Antigen retrieval was not performed for primary antibody against AQP4.
The sections were incubated with the primary antibodies for 1 hour at room temperature and then washed 3 times in PBS, stained with horseradish peroxidase-labeled polymer-conjugated anti-mouse or anti-rabbit secondary antibodies (EnVision+ System, Dako), and color developed with 3'-diaminobenzidine tetrahydrochloride.

\section{Histologic evaluation of biopsy specimens}

We reviewed H\&E-stained slides of the biopsy specimens and divided them into 4 groups according to the presence or absence of PCP, observed as distinct intraluminal protrusion of parietal cell cytoplasm at 3 or more glands, and the presence or absence of CDGs, observed as gland dilatation and cystic change ( $\geq 250 \mu \mathrm{m}$ in diameter) at 3 or more glands. Findings were recorded as $\mathrm{PCP}(-) \mathrm{CDG}(-)$, $\mathrm{PCP}(+) \quad \mathrm{CDG}(-), \quad \mathrm{PCP}(-) \quad \mathrm{CDG}(+)$, or $\mathrm{PCP}(+)$ $\mathrm{CDG}(+)$ and were further classified according to whether the patients had used a PPIs.

\section{Measuring the mucosal thickness of gastrectomy specimens}

We reviewed H\&E-stained slides prepared from the gastrectomy specimens and, with an ocular micrometer, measured the full thickness of the mucosa at 3 representative sites per case. For simplicity, we distinguished between the pit, the base, and the isthmus-and-neck as the region where foveolar cells were observed, the region where more than 3 contiguous chief cells were observed, and the region between the pit and base, respectively. We measured the length of each region at the same 3 sites where the full thickness of the mucosa was measured and then determined the percentage of the full-thickness mucosa represented by each of the 3 regions. By reviewing AQP4-stained slides, we also measured the lengths of AQP4-positive regions and determined the percentage of the full thickness represented by the AQP4positive regions.

\section{Counting the number of epithelial cells in gastrec- tomy specimens}

We reviewed H\&E-stained slides from the gastrectomy specimens and estimated the total number of epithelial cells by counting the epithelial cell nuclei in the lining of the oxyntic mucosa located within a span of $500 \mu \mathrm{m}$ at 3 representative sites per case. We then examined anti-MUC5AC-, anti- $\mathrm{H}^{+} / \mathrm{K}^{+}$ ATPase-, anti-MIST1-, and anti-Ki-67-stained tissues obtained at the same 3 representative sites, we coun- 
ted the number of positive cells, and we determined the percentages relative to the total number of epithelial cells.

\section{Measuring the area of $\mathrm{H}^{+} / \mathrm{K}^{+}$-ATPase-positive cells in gastrectomy specimens}

In reviewing anti- $\mathrm{H}^{+} / \mathrm{K}^{+}$-ATPase-stained slides of gastrectomy sections from each case, we photographed $500-\mu \mathrm{m}$-thick specimens of mucosa obtained from the 3 aforementioned representative sites with a digital microscope camera (OLYMPUS DP21, Tokyo, Japan). Using image analysis software (ImageJ; http://imagej.nih.gov/ij/,version 1.48), we adjusted color thresholds of the images (hue 0-255, saturation 50-255, brightness 0-255), and used the "Analyze Particles" function to measure the total surface area of all $\mathrm{H}^{+} / \mathrm{K}^{+}$-ATPase-positive cells, and we divided the total area by the number of $\mathrm{H}^{+} / \mathrm{K}^{+}$-ATPase-positive cells to determine the approximate cross-sectional cytoplasmic area of 1 cell.

Histologic and immunohistochemical comparisons of tissues from patients with PCPs vs. tissues from patients without PCPs

After identifying cases in which PCPs were present and cases in which PCPs were not present, we compared the histologic features of the tissue sections from the 2 types of cases. In addition, we examined immunohistochemically and evaluated quantitatively expression of markers of proper gastric epithelial cell differentiation as follows: MUC5AC in foveolar cells ${ }^{18)}$, AQP4 in parietal cells and chief cells ${ }^{19)}, \mathrm{H}+\mathrm{K}+$-ATPase in parietal cells ${ }^{20)}$, MUC6 in mucous neck cells ${ }^{18)}$, and MIST1 in chief cells ${ }^{21)}$. We also assessed cells for Ki-67 positivity ${ }^{22}$. Next, we carried out quantitative and comparative evaluations of the percentages of these cells making up oxyntic mucosa. Most parietal cells show diffusely positive cytoplasmic staining of $\mathrm{H}+/ \mathrm{K}+-\mathrm{ATPase}$. Although enlargement of parietal cells in PCP has been reported $^{12(16) 23)}$, the area of parietal cell cytoplasm in PCP has not been evaluated quantitatively or compara- tively. Thus, we measured the cytoplasmic area of $\mathrm{H}$ +/K+-ATPase-positive cells using image analysis software (ImageJ).

\section{Statistical Analyses}

Values obtained at each of the 3 representative sites of the gastrectomy specimens were averaged, and mean \pm SD values were determined for each group. Association between the appearance of PCPs or CDGs and PPI use was analyzed by chi-square test of independence. After significant differences between groups were confirmed by ANOVA, betweengroup differences in mucosal thickness and the number of epithelial cells were analyzed by Student's test. Differences in the cross-sectional cytoplasmic area of $\mathrm{H}^{+} / \mathrm{K}^{+}$-ATPase-positive cells were also analyzed by Student's test. Statcel 3 (OMS Ltd., Saitama, Japan) was used for all statistical analyses. Differences were considered significant at $p<0.05$.

\section{Results}

\section{Association between the emergence of PCPs or CDGs and PPI use}

The 468 patients from whom biopsy specimens were obtained and characteristics of these patients, including PPI use, are shown on Table 1. One hundred and eight of the 468 patients had PCPs. Seventyseven $(71.3 \%)$ of these 108 patients had used PPIs. The remaining 360 patients did not have PCPs, although $50(13.9 \%)$ of these patients had used PPIs. Significant association was found between the emergence of PCPs and PPI use, but no association was found between the emergence of CDGs and the use of PPIs (Table 2).

\section{Histologic and immunohistochemical characteris- tics of the oxyntic mucosa of the gastrectomy speci- mens showing PCPs}

Representative histologic and immunohistochemical findings in the $\mathrm{PCP}(+)$ group and $\mathrm{PCP}(-)$ group are shown in Figures $\mathbf{4}$ and 5.

Table 1. Characteristics of the 468 Study Patients Grouped Per the Presence and Absence of PCPs and CDGs.

\begin{tabular}{lcccc}
\hline & $\mathrm{PCP}(+)$ CDG(-) & $\mathrm{PCP}(+)$ CDG $(+)$ & $\mathrm{PCP}(-)$ CDG(-) & $\mathrm{PCP}(-)$ CDG(+) \\
& $\mathrm{n}=101$ & $\mathrm{n}=7$ & $\mathrm{n}=345$ & $\mathrm{n}=15$ \\
\hline Median age (range) & $70(31-85)$ years & $57(45-69)$ years & $67(13-89)$ years & $58(43-94)$ years \\
Sex ratio (M/F) & $59 / 42$ & $3 / 4$ & $201 / 144$ & $4 / 11$ \\
PPI use & $\mathrm{n}=72,71.3 \%$ & $\mathrm{n}=5,71.4 \%$ & $\mathrm{n}=46,13.3 \%$ & $\mathrm{n}=4,26.7 \%$ \\
\hline
\end{tabular}

PCP, parietal cell protrusion; CDG, cystically dilated gland; PPI, proton pump inhibitor. 
Table 2. Association Between PPI Use and Emergence of PCPs and CDGs.

\begin{tabular}{lccc}
\hline & PPI use & PPI non-use & p value* \\
\hline PCP $(+)$ & $n=77$ & $n=31$ & $<0.001$ \\
PCP $(-)$ & $n=50$ & $n=310$ & \\
CDG $(+)$ & $n=9$ & $n=13$ & 0.14 \\
CDG $(-)$ & $n=118$ & $n=328$ &
\end{tabular}

PPI, proton pump inhibitor; PCP, parietal cell protrusion; CDG, cystically dilated gland.

*obtained by chi-square test of independence.
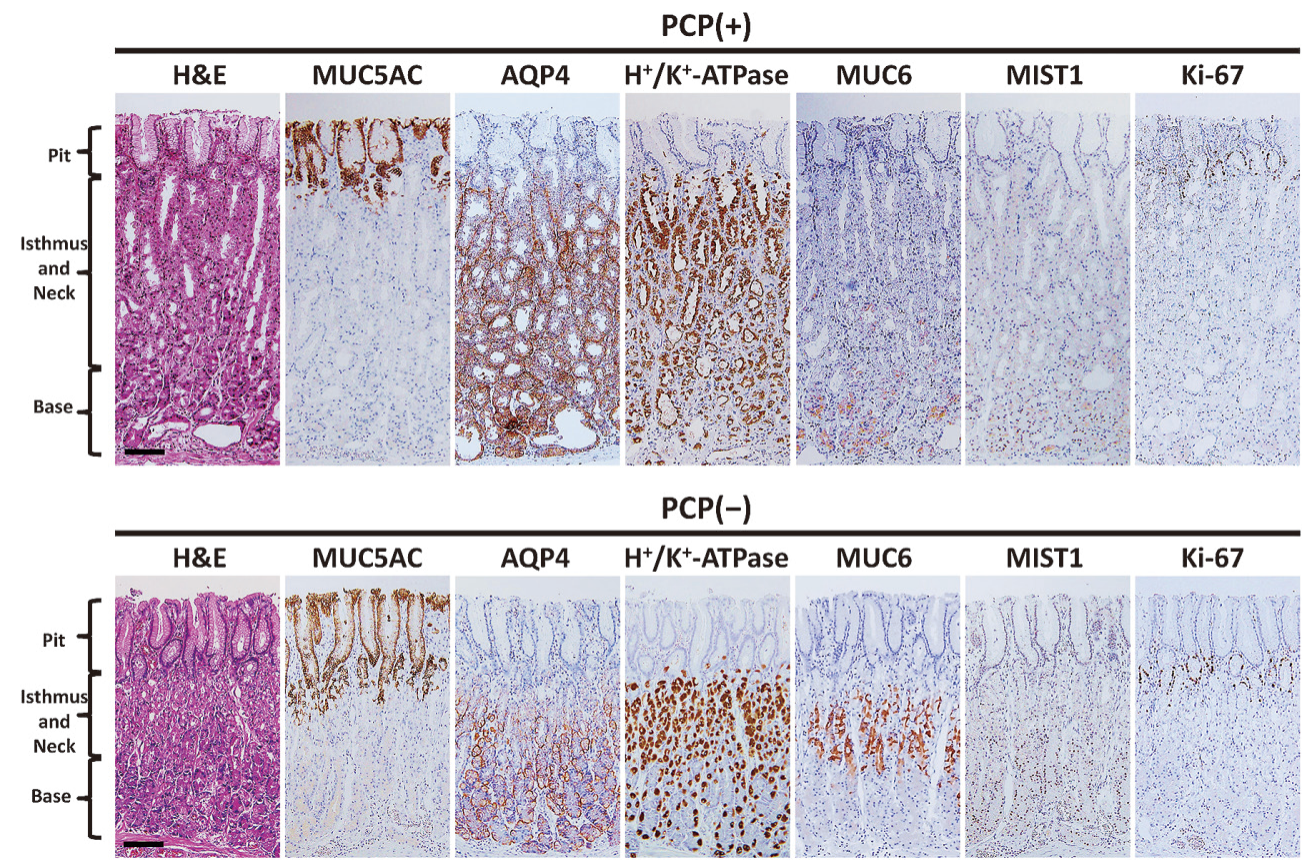

Figure 4. Representative histologic and immunohistochemical features of oxyntic mucosa with vs. without PCPs.

H\&E stain. Elongation of the isthmus-and-neck region and shortening of the pit and base regions are noted in the $\mathrm{PCP}(+)$ group. Each black bar $=100 \mu \mathrm{m}$

MUC5AC. The pit region tends to be shortened in the $\mathrm{PCP}(+)$ group.

AQP4. The region of cells strongly positive for AQP4 is expanded in the $\mathrm{PCP}(+)$ group.

$\mathbf{H}^{+} / \mathrm{K}^{+}$-ATPase. Positive $\mathrm{H}^{+} / \mathrm{K}^{+}$-ATPase staining is increased in the $\mathrm{PCP}(+)$ group.

MUC6. Cells positive for MUC6 are increased in the base region in the $\mathrm{PCP}(+)$ group.

MIST1. Positively stained cells are fewer in number in the $\mathrm{PCP}(+)$ group.

Ki-67. There is no significant difference in the distribution of Ki-67 positive cells between the 2 groups.

\section{Mucosal thickness}

Mucosal thicknesses are shown per group in Table 3 and Figure 6. The overall full-thickness mucosa was thicker in the $\mathrm{PCP}(+)$ group than in the $\mathrm{PCP}(-)$ group, but the difference was not statistically significant (Table 3, Figure 6A). Thickness of the pit region did not differ significantly between the 2 groups, but a significant decrease $(p=0.03)$ in the percentage of pit region relative to the overall thickness of the mucosa was observed in the $\mathrm{PCP}(+)$ group (Table 3, Figure 6B). The thickness and percentage of the isthmus-and-neck region were significantly increased $(p<0.001)$ in the $\mathrm{PCP}(+)$ group (Table 3, Figure 6C). By comparison, significant decreases $(p=0.003$ and $<0.001)$ in the thickness and percentage of the base region were observed in the $\mathrm{PCP}(+)$ group (Table 3, Figure 6D).

Increased AQP4 expression was seen just below 


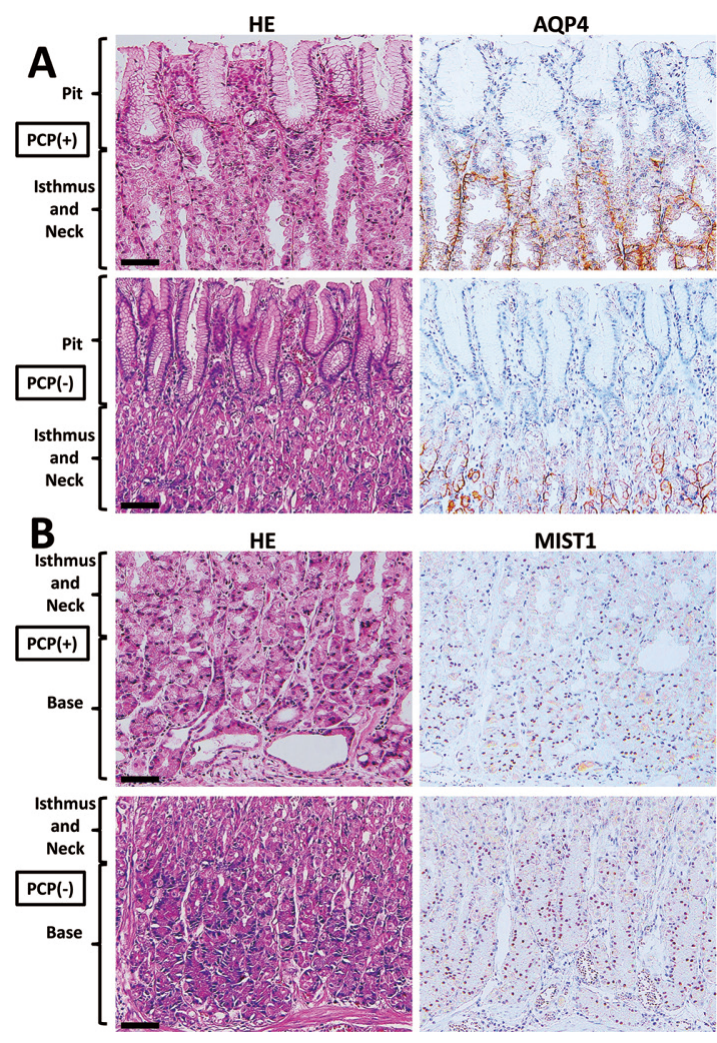

Figure 5. Enlarged representative images of AQP4- and MIST1-stained sections in the 2 groups.

A, AQP4 expression. In the $\mathrm{PCP}(+)$ group, strong expression of AQP4 tends to begin just beneath the pit region. B, MIST1 expression. MIST1-positive cells are clearly less numerous in the $\mathrm{PCP}(+)$ group than in the $\mathrm{PCP}(-)$ group. Each black bar $=100 \mu \mathrm{m}$
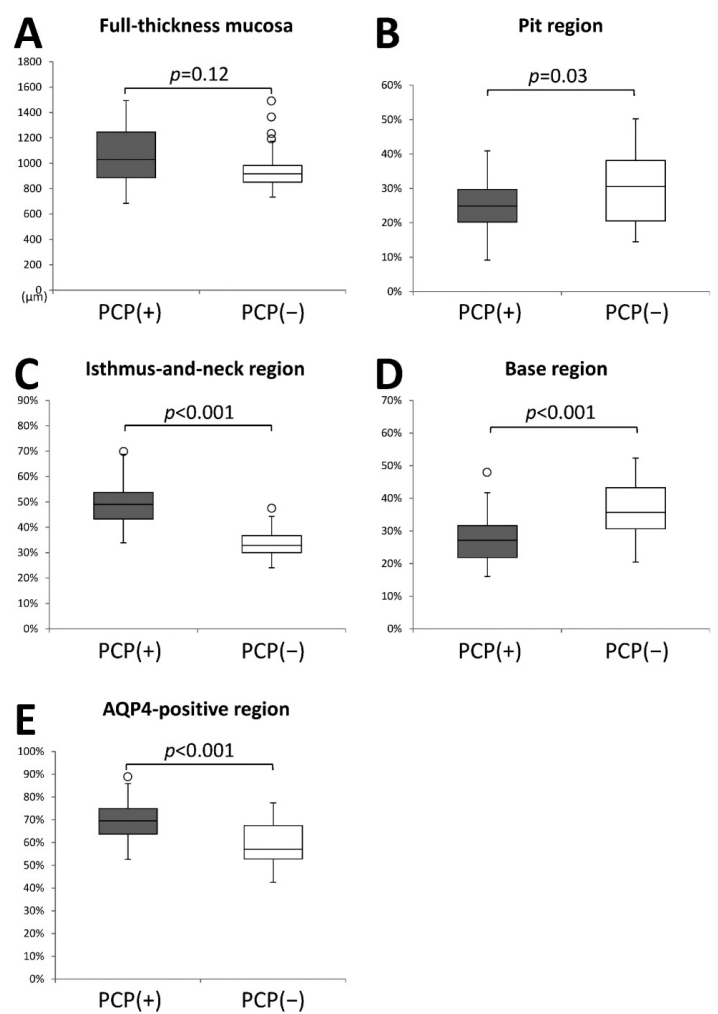

Figure 6. Mucosal thicknesses in the $\mathrm{PCP}(+)$ group vs. $\mathrm{PCP}(-)$ group.

A, Full-thickness mucosa. B, Percentage of the pit region. C, Percentage of the isthmus-andneck region. D, Percentage of the base region. E, Percentage of the APQ4-positive region. Box, interquartile range (IQR). Mid-line, median. Whiskers, minimum and maximum values within $1.5^{*} \mathrm{IQR}$ of lower and upper quartiles. $\circ$, outlier.

Table 3. Mucosal Thicknesses in the $\mathrm{PCP}(+)$ and $\mathrm{PCP}(-)$ Groups

\begin{tabular}{lcccc}
\hline & \multicolumn{2}{c}{$\mathrm{PCP}(+)$} & \multicolumn{2}{c}{$\begin{array}{c}\mathrm{PCP}(-) \\
\mathrm{n}=26\end{array}$} \\
\hline & Thickness $(\mu \mathrm{m})$ & Percentage $(\%)$ & Thickness $(\mu \mathrm{m})$ & Percentage $(\%)$ \\
\hline Full mucosa & $1058.8 \pm 236.8$ & & $965.4 \pm 181.6$ & \\
Pit region & $252.4 \pm 108.5$ & $23.6 \pm 8.6$ & $287.6 \pm 120.3$ & $29.5 \pm 9.8$ \\
Isthmus-and-neck region & $525.5 \pm 180.0$ & $49.0 \pm 9.2$ & $328.8 \pm 103.8$ & $33.7 \pm 6.2$ \\
Base region & $280.9 \pm 75.2$ & $27.4 \pm 7.8$ & $349.0 \pm 81.9$ & $36.8 \pm 9.3$ \\
APQ4-positive region & $783.7 \pm 201.1$ & $69.9 \pm 9.9$ & $564.1 \pm 119.1$ & $59.3 \pm 10.2$ \\
\hline
\end{tabular}

PCP, parietal cell protrusion.

Mean \pm SD values are shown.

the pit region in specimens from the $\mathrm{PCP}(+)$ group but not in specimens from the $\mathrm{PCP}(-)$ group (Figure 5A). The thickness and percentage of the APQ4-positive region were significantly greater in the $\mathrm{PCP}(+)$ group than in the $\mathrm{PCP}(-)$ group (Table 3, Figure 6E). 
Table 4. Number and Percentage of the Various Cell Types in the $\mathrm{PCP}(+)$ and $\mathrm{PCP}(-)$ Groups.

\begin{tabular}{lcccc}
\hline & \multicolumn{2}{c}{$\begin{array}{c}\mathrm{PCP}(+) \\
\mathrm{n}=26\end{array}$} & \multicolumn{2}{c}{$\begin{array}{c}\mathrm{PCP}(-) \\
\mathrm{n}=26\end{array}$} \\
\hline All cells & Number of cells & Percentage $(\%)$ & Number of cells & Percentage $(\%)$ \\
MUC5AC+ cells & $1320 \pm 369.7$ & & $1358.8 \pm 277.1$ & \\
$\mathrm{H}^{+} / \mathrm{K}^{+}$-ATPase+ cells & $185.0 \pm 77.4$ & $24.8 \pm 10.4$ & $222.2 \pm 74.9$ & $28.9 \pm 11.2$ \\
MIST1+ cells & $216.4 \pm 69.2$ & $28.5 \pm 7.5$ & $156.8 \pm 31.6$ & $20.1 \pm 4.2$ \\
Ki-67+ cells & $94.0 \pm 46.8$ & $12.6 \pm 6.3$ & $174.1 \pm 66.3$ & $21.7 \pm 6.4$ \\
\hline
\end{tabular}

$\mathrm{PCP}$, parietal cell protrusion.

Mean \pm SD values are shown.

Numbers of proper epithelial cells, cells expressing various cell differentiation markers, and Ki-67-positive cells in the oxyntic mucosa

The numbers and percentages of the various cell types are shown in Table 4 and Figure 7A-E. There was no significant difference in the total number of mucosal epithelial cells between the $\mathrm{PCP}(+)$ group and $\mathrm{PCP}(-)$ group. Both the number and percentage of MUC5AC-positive cells (foveolar cells) were lower in the $\mathrm{PCP}(+)$ group than in the $\mathrm{PCP}(-)$ group, but the differences were not significant. The number and percentage of $\mathrm{H}^{+} / \mathrm{K}^{+}$-ATPase-positive cells (parietal cells) were significantly higher $(p<0.001)$ in the $\mathrm{PCP}(+)$ group than in the $\mathrm{PCP}(-)$, and the number and percentage of MIST1-positive cells (chief cells) were significantly lower $(p<0.001)$ in the $\mathrm{PCP}(+)$ group than in the $\mathrm{PCP}(-)$ group. Ki-67-positive epithelial cells (proliferating cells) were seen only at the top of the isthmus-and-neck region, and there was no significant difference in the number or percentage of these cells between the 2 groups. No Ki-67-positive parietal cells were seen in either group.

\section{Cytoplasmic area of the parietal cells}

The cytoplasmic area of the parietal cells, shown in Figure 7F, was significantly larger in the $\mathrm{PCP}(+)$ group than in the $\mathrm{PCP}(-)$ group $\left(288.8 \pm 71.1 \mu \mathrm{m}^{2} /\right.$ cell vs. $191.0 \pm 53.9 \mu \mathrm{m}^{2} /$ cell, respectively; $p<0.001$ ).

\section{MUC6 expression}

MUC6-expressing cells in the base region were more numerous in the $\mathrm{PCP}(+)$ group than in the $\mathrm{PCP}(-)$ group (Figure 4).

\section{Discussion}

To the best of our knowledge, there have been no reported studies quantifying PCPs or CDGs in routine gastric biopsy specimens including specimens obtained from patients who do not use PPIs, although
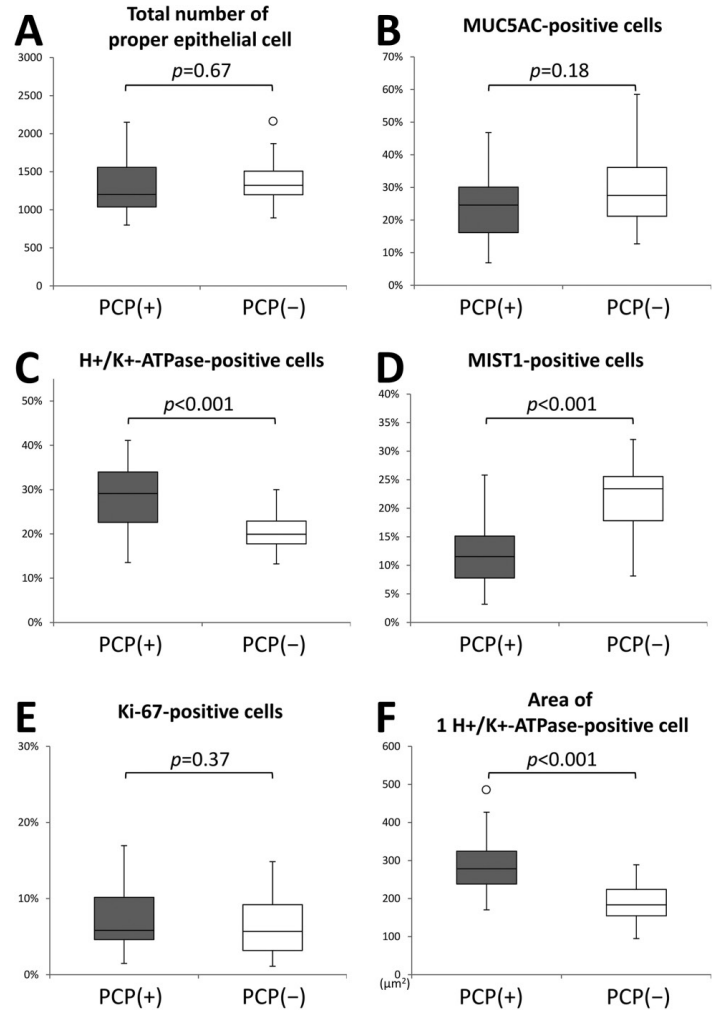

Figure 7. Number of proper epithelial cells in the oxyntic mucosa and results of immunohistochemical analyses in the $\mathrm{PCP}(+)$ group vs. $\mathrm{PCP}(-)$ group $\mathbf{A}$, Total number of proper epithelial cell in the oxyntic mucosa. B, Percentage of MUC5ACpositive cells. C, Percentage of $\mathrm{H}+/ \mathrm{K}+-\mathrm{AT}$ Pase-positive cells. D, Percentage of MIST1positive cells. E, Percentage of Ki-67-positive cells. F, Area of $1 \mathrm{H}+/ \mathrm{K}+-$ ATPase-positive cell cytoplasm. Box, interquartile range (IQR). Mid-line, median. Whiskers, minimum and maximum values within $1.5 * \mathrm{IQR}$ of lower and upper quartiles. $\circ$, outlier. 
there have been reports of a significant relation between PPI use and the emergence of PCPs or $\mathrm{CDGs}^{7-17223)}$. Therefore, we reviewed all cases in which biopsy specimens of gastric oxyntic mucosa were obtained during a 1-year period at our medical facility. Our study confirmed a significant relation between the emergence of PCPs and PPI use. We observed PCPs in 108 (23.1\%) of our 468 patients and thus realized that emergence of PCPs is not an uncommon histologic finding and that the prevalence might be due to the widespread use of PPIs. However, for $31(29 \%)$ of the 108 patients, there was no record of PPI use. It is unknown whether these 31 patients might have used PPIs before consultation at our hospital. These results imply the presence of factors other than PPIs that give rise to PCPs. Interestingly, Kumar et al. reported that CDGs and PCPs were equally prevalent in PPI users and non-users with Helicobacter pylori gastritis, suggesting that $H$. pylori infection might be also a possible cause of $\mathrm{PCPs}^{24}$. Currently, the mechanism explaining how $H$. pylori infection causes PCPs remains to be fully clarified, and further studies are expected. Contrary to previously reported studies, our study showed absence of a significant association between the emergence of CDGs and the use of PPIs ${ }^{7-11), 17)}$. We observed CDGs in patients who did not use PPIs; thus, CDGs might be a relatively common histologic changes that results from various factors including, but not limited to, the use of PPIs.

Previous studies of PCPs in biopsy specimens did not include histologic examination of the fullthickness oxyntic mucosa. Therefore, we quantitatively evaluated gastric oxyntic mucosa characterized by PCP by counting epithelial cells of the full-thickness mucosa of surgically resected specimens. We found an increase in the number of parietal cells at the neck region of the fundic glands in the $\mathrm{PCP}(+)$ group, confirming that $\mathrm{PCP}$ is indeed a hyperplastic lesion. In addition, the cytoplasmic area of parietal cells in the $\mathrm{PCP}(+)$ group was significantly enlarged. These 2 characteristic changes may explain the elongation of isthmus-and-neck region that we observed. Further, the decreased number of chief cells, which distribute mainly in the base region of the fundic gland, observed in the $\mathrm{PCP}(+)$ group might explain the shortening of the base regions of the fundic glands.

Stem cells located in the isthmus of the gland give rise to mature cells as they migrate toward the pit or base of the gland ${ }^{1)}$. In addition, functional and developmental diversity has been reported between parietal cells located in the lower vs. upper part of the gland $^{14425) 26}$. Water channel protein AQP4 is expressed mainly in parietal cells located in the lower part of the glands in normal oxyntic mucosa of human, mouse, and rat stomach ${ }^{19272728}$. In humans, AQP4 is also expressed in chief cells ${ }^{19}$. Matsuzaki et al reported that distribution of AQP4-positive parietal cells in the mouse stomach toward the upper part of the glands indicates a disturbance in parietal cell differentiation $^{4)}$. AQP4-positive parietal cells tended to distribute much higher in the gland in our $\mathrm{PCP}(+)$ group than in our $\mathrm{PCP}(-)$ group. In addition, the thickness of the APQ4-positive region was significantly increased in our $\mathrm{PCP}(+)$ group. These changes point to a disturbance in parietal cell differentiation in human oxyntic mucosa showing PCP.

Chief cells differentiate from mucous cells at the neck region as they migrate down to the base region ${ }^{11}$. In normal oxyntic mucosa, expression of MUC6, a marker of mucous neck cells, gradually decreases with the mucous neck-to-chief cell differentiation; no MUC6 expression is observed in mature chief cells $^{2129)}$. In contrast, expression of MIST1, a chief cell marker that is not expressed in mucous neck cells, gradually increases with mucous neck-to-chief cell differentiation ${ }^{2129}$. In our study, the MUC6 expression was maintained in the base region in the $\mathrm{PCP}(+)$ group along with a decrease in the number of MIST1-positive cells and suggests impairment of the mucous neck-to-chief cell differentiation in the human gastric oxyntic mucosa with PCP. The increase in the number of parietal cells and the decrease in the number of chief cells along with the disturbance in their differentiation result in the proportional change in gastric proper epithelial cells in oxyntic glands. These results are consistent with results of a recent study in lansoprazole-treated mice ${ }^{4}$.

We observed a significant increase in the number of $\mathrm{H}+/ \mathrm{K}+$-ATPase-positive cells in our $\mathrm{PCP}(+)$ group, which differed from the results of a recent experimental study in which the number of $\mathrm{H}+/ \mathrm{K}+-\mathrm{AT}$ Pase-positive cells did not differ significantly between lansoprazole-treated mice and control mice ${ }^{4)}$. The discrepancy might be due in part to the difference between mice and humans, but the details remain unclear.

As noted above, PCP is frequently accompanied by cytoplasmic vacuoles. We considered whether the vacuolation gives rise to the protrusion of parietal cell cytoplasm. Previous reports suggested that the factor 
responsible for protrusion of the cytoplasm is the trophic effect of gastrin on intracytoplasmic secretory canaliculi $^{14)}$. Cats et al. showed that PCP develops with a rise in serum gastrin levels during omeprazole therapy ${ }^{15)}$. Other studies showed that PCP sometimes occurs in patients with hypergastrinemia due to a condition such as autoimmune gastritis or ZollingerEllison syndrome. ${ }^{1430)}$ Kato et al. examined the ultrastructure of parietal cells during treatment with omeprazole and noted marked dilation of the secretory canaliculi, as seen in the active secretion phase. ${ }^{31)}$ Kirshnmurthy et al. noted an increase in secretory canaliculi reflecting the activation of parietal cells induced by secondary hypergastrinemia due to acid suppression therapy. ${ }^{14)}$ However, the ultrastructural features of parietal cells in patients treated with omeprazole have varied from study to study. One study showed features similar to those in the resting phase. ${ }^{12)}$ Another revealed a significant increase in autophagic vacuole/autolysosome-like structures, which is not observed in either the secreting or resting phase. ${ }^{32}$ We found no obvious endocrine cell hyperplasia, which is a well-known histopathologic feature of gastric mucosa in the presence of hypergastrinemia, except in 1 case of Zollinger-Ellison syndrome. Furthermore, in a retrospective study, PCP was observed in $35 \%$ of patients treated with omeprazole after distal gastrectomy, which results in decreased gastrin production ${ }^{23}$. Findings from these studies suggest that causative factors other than hypergastrinemia play significant roles in PCP formation; thus, further studies are needed for clarification of the underlying mechanism.

In our $\mathrm{PCP}(+)$ group, the AQP4-positive cell region expanded from the glandular isthmus to the glandular base in the oxyntic mucosa. The increase in the number of parietal cells may have been an increase in the number of AQP4-positive parietal cells. The possible involvement of AQP4 in water transport in parietal cells ${ }^{19)}$ suggests that influx of water into the lumen of the oxyntic glands may occur in $\mathrm{PCP}(+)$ tissues. In fact, fluid retention is often found in cases of CDGs with PCP, as shown in Figure 3A, B. In addition, high gland luminal pressure has been documented in the gastric mucosa of rats given omeprazole $^{33)}$. These findings suggest that elevated hydrostatic pressure and cytoplasmic edema due to movement of water from the interstitial space toward the lumen of oxyntic glands through the parietal cells give rise to the formation of PCPs, oxyntic dilatation, and CDGs. To the contrary, aberrant distribution of mitotically active stem cells can occur, which causes the deeper distribution of mucous-secreting cells in sporadic gastric $\mathrm{FGPs}^{34)}$. CDGs in FGPs are thought to be formed by consequent mucous retention. Thus, it is possible that CDGs with PCP and sporadic FGPs are formed by different mechanisms.

PPIs have been considered safe drugs. However, in a long-term study, an increased incidence of cancer was observed among PPI users ${ }^{35}$. Hagiwara et al. recently demonstrated in Mongolian gerbils ${ }^{36)}$ that long-term PPI administration promotes development of adenocarcinoma, but whether clinical use of PPIs increases the risk of gastric cancer is currently uncertain due to very limited evidences. Therefore, further clinical investigations are expected in the future.

\section{Conclusion}

In the present study, a significant relation between the emergence of PCPs and PPI use was confirmed by a comparative examination of gastric mucosa specimens obtained from patients using PPIs and patients not using PPIs. In addition, PCP was shown to be a hyperplastic parietal cell lesion. Furthermore, our study reinforced the possibility that elevated hydrostatic pressure and cytoplasmic edema due to movement of water from interstitial space toward the lumen of oxyntic glands via parietal cells give rise to the formation of PCPs, oxyntic dilatation, and CDGs. The detailed mechanism of PCP formation and its related findings are expected to be clarified in future studies.

\section{References}

1) Karam SM, Straiton T, Hassan WM, Leblond CP. Defining epithelial cell progenitors in the human oxyntic mucosa. Stem Cells 2003; 21: 322-336.

2) Vanderhoff BT, Tahboub RM. Proton pump inhibitors: An update. Am Fam Physician 2002; 66: 273-280.

3) Hoogerwerf WA, Pasricha PJ. Pharmacotherapy of gastric acidity, peptic ulcers, and gastroesophageal reflux disease. In: Brunton LL, Lazo SS, Parker KL (eds). Goodman \& Gilman's The Pharmacological Basis of Therapeutics, 11th ed, McGraw-Hill, New York, 2006: 967-981.

4) Matsuzaki J, Suzuki H, Minegishi Y, Sugai E, Tsugawa H, Yasui M, et al. Acid suppression by proton pump inhibitors enhances aquaporin-4 and KCNQ1 expression in gastric fundic parietal cells in mouse. Dig Dis Sci 2010; 55: 3339- 
3348.

5) Stolte M, Bethke B, Seifert E, Armbrecht U, Lutke A, Goldbrunner P, et al. Observation of gastric glandular cysts in the corpus mucosa of the stomach under omeprazole treatment. Z Gastroenterol 1995; 33: 146-149.

6) Drut R, Altamirano E, Cueto Rua E. Omeprazole-associated changes in the gastric mucosa of children. J Clin Pathol 2008; 61: 754-756.

7) Choudhry U, Boyce HW Jr, Coppola D. Proton pump inhibitor-associated gastric polyps: A retrospective analysis of their frequency, and endoscopic, histologic, and ultrastructural characteristics. Am J Clin Pathol 1998; 110: 615-621.

8) el-Zimaity HM, Jackson FW, Graham DY. Fundic gland polyps developing during omeprazole therapy. Am J Gastroenterol 1997; 92: 18581860.

9) Jalving M, Koornstra JJ, Wesseling J, Boezen HM, DE Jong S, Kleibeuker JH. Increased risk of fundic gland polyps during long-term proton pump inhibitor therapy. Aliment Pharmacol Ther 2006; 24: 1341-1348.

10) Hongo M, Fujimoto K. Gastric Polyps Study Group. Incidence and risk factor of fundic gland polyp and hyperplastic polyp in long-term proton pump inhibitor therapy: A prospective study in Japan. J Gastroenterol 2010; 45: 618-624.

11) Graham JR. Gastric polyposis: Onset during long-term therapy with omeprazole. Med J Aust 1992; 157: 287-288.

12) Driman DK, Wright C, Tougas G, Riddell RH. Omeprazole produces parietal cell hypertrophy and hyperplasia in humans. Dig Dis Sci 1996; 41: 2039-2047.

13) Stolte M, Bethke B. Elimination of helicobacter pylori under treatment with omeprazole. Z Gastroenterol 1990; 28: 271-274.

14) Krishnamurthy S, Dayal Y. Parietal cell protrusions in gastric ulcer disease. Hum Pathol 1997; 28: 1126-1130.

15) Cats A, Schenk BE, Bloemena E, Roosedaal R, Lindeman J, Biemond I, et al. Parietal cell protrusions and fundic gland cysts during omeprazole maintenance treatment. Hum Pathol 2000; 31: 684-690.

16) Stolte M, Meining A, Seifert E, Alexandridis T. Treatment with lansoprazole also induces hypertrophy of the parietal cells of the stomach. Pathol Res Pract 2000; 196: 9-13.

17) Fenoglio-Preiser CM, Noffsinger AE, Stemmer- mann GN, Lantz PE, Isaacson PG. Gastrointestinal Pathology: An Atlas and Text, 3rd ed, Lippincott Williams \& Wilkins, Philadelphia, 2008: 135-231.

18) Yonezawa S, Higashi M, Yamada N, Yokoyama S, Kitamoto S, Kitajima S, et al. Mucins in human neoplasms: Clinical pathology, gene expression and diagnostic application. Pathol Int 2011; 61: 697-716.

19) Misaka T, Abe K, Iwabuchi $K$, Kusakabe $Y$, Ichinose $\mathrm{M}$, Miki $\mathrm{K}$, et al. A water channel closely related to rat brain aquaporin 4 is expressed in acid- and pepsinogen-secretory cells of human stomach. FEBS Lett 1996; 381: 208212.

20) Choi E, Roland JT, Barlow BJ, O'Neal R, Rich AE, Nam KT, et al. Cell lineage distribution atlas of the human stomach reveals heterogeneous gland populations in the gastric antrum. Gut 2014; 63: 1711-1720.

21) Ramsey VG, Doherty JM, Chen CC, Stappenbeck TS, Konieczny SF, Mills JC. The maturation of mucus-secreting gastric epithelial progenitors into digestive-enzyme secreting zymogenic cells requires Mist1. Development 2007; 134: 211-222.

22) Scholzen T, Gerdes J. The Ki-67 protein: From the known and the unknown. J Cell Physiol 2000; 182: 311-322.

23) Stolte M, Bethke B, Ruhl G, Ritter M. Omeprazole-induced pseudohypertrophy of gastric parietal cells. Z Gastroenterol 1992; 30: 134-138.

24) Kumar KR, Iqbal R, Coss E, Park C, Cryer B, Genta RM. Helicobacter gastritis induces changes in the oxyntic mucosa indistinguishable from the effects of proton pump inhibitors. Hum Pathol 2013; 44: 2706-2710.

25) Shao JS, Schepp W, Alpers DH. Expression of intrinsic factor and pepsinogen in the rat stomach identifies a subset of parietal cells. Am J Physiol 1998; 274: G62-70.

26) Jain RN, Samuelson LC. Differentiation of the gastric mucosa. II. Role of gastrin in gastric epithelial cell proliferation and maturation. Am J Physiol Gastrointest Liver Physiol 2006; 291: G762-765.

27) Wang KS, Komar AR, Ma T, Filiz F, McLeroy J, Hoda $\mathrm{K}$, et al. Gastric acid secretion in aquaporin-4 knockout mice. Am J Physiol Gastrointest Liver Physiol 2000; 279: G448-453.

28) Frigeri A, Gropper MA, Umenishi F, Kawa- 
shima M, Brown D, Verkman AS. Localization of MIWC and GLIP water channel homologs in neuromuscular, epithelial and glandular tissues. J Cell Sci 1995; 108 (Pt 9): 2993-3002.

29) Kushima R, Sekine S, Matsubara A, Taniguchi $\mathrm{H}$, Ikegami M, Tsuda H. Gastric adenocarcinoma of the fundic gland type shares common genetic and phenotypic features with pyloric gland adenoma. Pathol Int 2013; 63: 318-325.

30) Stolte M, Baumann K, Bethke B, Ritter M, Lauer E, Eidt H. Active autoimmune gastritis without total atrophy of the glands. Z Gastroenterol 1992; 30: 729-735.

31) Kato S, Fujii T, Nakano K, Naganuma H, Nakagawa $\mathrm{H}$. The effects of omeprazole on the ultrastructure of gastric parietal cells. J Pediatr Gastroenterol Nutr 1994; 19: 91-96.

32) Kobayashi H, Watanabe T, Nakahara A, Mutoh $\mathrm{H}$, Tanaka N, Uchiyama Y. Fine structural and morphometric studies on gastric parietal cells of peptic ulcer patients after long-term treatment with omeprazole. Arch Histol Cytol 1998; 61: 287-295.

33) Synnerstad I, Holm L. Omeprazole induces high intraglandular pressure in the rat gastric mucosa. Gastroenterology 1997; 112: 1221-1230.

34) Odze RD, Marcial MA, Antonioli D. Gastric fundic gland polyps: A morphological study including mucin histochemistry, stereometry, and MIB-1 immunohistochemistry. Hum Pathol 1996; 27: 896-903.

35) Poulsen AH, Christensen S, McLaughlin JK, Thomsen RW, Sorensen HT, Olsen JH, et al. Proton pump inhibitors and risk of gastric cancer: A population-based cohort study. Br J Cancer 2009; 100: 1503-1507.

36) Hagiwara $T$, Mukaisho $K$, Nakayama $T$, Sugihara $\mathrm{H}$, Hattori $\mathrm{T}$. Long-term proton pump inhibitor administration worsens atrophic corpus gastritis and promotes adenocarcinoma development in mongolian gerbils infected with helicobacter pylori. Gut 2011; 60: 624-630. 